\title{
Design and Prototype of a Magnetic Adhesion Tracked-Wheel Robotic Platform for Mooring Chain Inspection
}

\author{
Mahesh Dissanayake ${ }^{1}$, Tariq Sattar ${ }^{1}$, Tat-Hean Gan ${ }^{2}$, Ivan Pinson ${ }^{2}$, Shehan Lowe \\ London South Bank University, London ${ }^{1}$, TWI Ltd, Cambridge ${ }^{2}$
}

\begin{abstract}
The development of climbing robots for mooring chain applications is still in its infancy due to the operational complexity and the geometrical features of the chain. Mooring chains are subjected to high tidal waves, harsh environmental conditions and storms on a daily basis. Therefore, the integrity assessment of chain links is vital and regular inspection is mandatory for offshore structures. The Magnetic adhesion tracked-wheel crawler robot presented in this study is suitable for mooring chain climbing in air and the technique can be adapted for underwater use. The robotic platform can climb mooring chains at a maximum speed of $42 \mathrm{~cm} /$ minute with an external load of $50 \mathrm{~N}$. A numerical study was conducted to investigate the adhesion module and analysis of the robot structural design. Numerical results were validated using a prototyped robot in laboratory conditions. The proposed robot can be used as a platform to convey equipment for non-destructive testing applications.
\end{abstract}

Key Words

Mooring chain; Chain climbing robot; Crawler Robot; Magnetic adhesion robot; Trackedwheel crawler; Inspection platform; Numerical modelling; Robot design.

\section{Introduction}

An exponential increase of floating oil and gas production systems has been recorded around the world due to the high demand for energy consumption. In total 277 floating production units (FPU) were recorded by November 2013 and 62\% of these were categorized as Floating Production Storage and Offloading (FPSO) [1]. The history of the mooring chain began in 1808 with advances in the shipping industry when it became necessary to maintain a floating structure within a given (pre-specified) position. The necessity to ensure the integrity of a chain arises as a result of the in-situ conditions that mooring chains are subjected to on a regular basis, such as high tidal waves, storms, hurricanes, effect of salt water and harsh environmental conditions. Chain overload, outof-plane bending, wear effect between chain links, corrosion and manufacturing defects are the main contributors to the breaking of mooring chains which can then lead to significant damage such as vessel drift, riser rupture, production shutdown and hydrocarbon release, etc. As an example, the "Gryphon Alpha" had to spend \$1.8 billion to resume after it's mooring failure [2]. In the period 2001-2011, there were 21 accidents recorded with 8 human fatalities [3]. Most modern systems are designed to handle a single 
breaking but multiple breaking can easily lead to a catastrophic incident. According to the reported data from the North Sea (1980-2001), every 4.7 years, a floating production system has experienced a mooring failure [4]. Approximately $£ 2 \mathrm{M}-10.5 \mathrm{M}$ loss can occur due to a single mooring failure [5]. After considering the potential damage to humans as well as the environment, periodic inspection becomes mandatory for mooring systems [4]. Mooring chains are not designed to monitor their condition, therefore mooring integrity management of FPSO (floating production storage and offloading) needs to be addressed with a capability to handle in-situ conditions, because most offshore oil production systems are not able to move for inspection or repair. The most common underwater inspection method is manual non-destructive testing (NDT) with trained divers but due to health and safety concerns, divers are not allowed to inspect a chain in the splash zone area [4]. Removing and replacing mooring chains for inspection is a costly and not very reliable method due to the difficult operating conditions. Therefore, it is important to develop an autonomous robotic platform that has the capability to access the chain physically and deploy most of the reliable integrity management NDT methods such as ultrasound testing [6], guided wave inspection [7], mechanical measurements, etc.

The aim of this paper is to describe the development of a lightweight, permanent magnetic adhesion, wheeled robot which can be used as a platform to convey NDT equipment along the mooring chain to perform NDT in air and also be adapted for underwater operation. The paper is organized as follows. Section 2 reviews the state-ofthe-art of mooring chain robots, Section 3 presents the design of a mooring chain climbing robot, its structural strength analysis, motor drive and magnetic adhesion systems. Section 4 describes the development of a prototype robot. Testing and validation of the robot system is reported in section 5. Section 6 concludes the paper and suggests further work that is required.

\section{Related work}

Due to the complexity of the mooring chain structure, only a few attempts have been made to establish a robotic/automated system which can operate both in air and underwater. Most of them are at research stages and unable to extend beyond the initial laboratory experimental stage. Moreover, when considering the climbing and crawling robots, chain climbing is an area which needs to be developed. The inchworm influenced amphibious robot MOORINSPECT developed in 2013 uses two gripper arms to climb [8-9]. It weighs $450 \mathrm{~kg}$ in air and approximately $750 \mathrm{~kg}$ with its long-range ultrasound collar and hydraulic deployment system. An anchor chain inspection and cleaning robot was presented in 2004 [10] as a human-like climbing mechanism. A mooring chain inspection robot presented in [11] can only be used at the chain manufacturing stage to inspect welding joints on chain links. A gravity assisted cable mechanism was presented in 2008 [12] but the allocated gravity assisted crawler-cable mechanism was unable to perform as expected [13]. The WELAPTEGA subsea mooring inspection system is deployed with a remotely operated vehicle (ROV) and uses automated mooring chain measuring devices (visual and NDT measurements) [14]. When considering the offshore environment and a mooring chain's catenary curvature, heavy and longer robots are not easily deployable [4]. The abovementioned robots are deployed by mechanical means by using divers. Due to the 
operational conditions, it is not practical to handle large weights in a cost-effective manner. Therefore, additional deployment tools and supports are needed. The ROVs are unable to access the chain in air, therefore these systems can only be used for underwater inspection. Moreover, accessing the splash zone may not be possible with a ROV due to the limitation of underwater ROV manipulation. Visually aided ROV inspection is common in industry but according to the history of mooring chain accidents and breakings, conventional ROV inspection cannot be considered as a reliable method [3-4]. The above mentioned state-ofthe-art robotic approaches are not able to provide a practical solution which can cover the entire chain in in-situ conditions. Therefore, it is essential to create a lightweight, fast and automated system which can climb/walk/crawl in both air and underwater in operational conditions.

\section{Design process of the climbing platform}

\subsection{Design requirements}

Physical nature of the mooring chain and in-situ environmental conditions create a significant requirement for an automated robotic system that has high structural tolerance. Mooring chains are often subjected to large environmental changes such as tidal waves, wind, storms, etc. The chain link shown in Figure 1 demonstrates rusted and uneven surfaces. Therefore, robustness of the climbing robot needs to be ensured. Due to the harsh offshore conditions that the robot has to operate in, easy robot deployment is identified as one of the main design requirement. Deployment of a large and heavy robot is much harder in offshore environments. Also, a robot structure that encloses the chain is harder to deploy. Ability to change surfaces between orthogonal chain-links is considered as the second requirement because mooring chains are discontinuous being made with 2 sets of links that are kept orthogonal to each other. So, the crawling/climbing robot needs to cope with the discontinuity. An amphibious adhesion module and suitable locomotion are also identified as the areas that need to be addressed during the design. The adhesion module and locomotion mechanism needs to be selected according to the mooring chain's physical nature, i.e., curved, rusted, ferromagnetic, amphibious, and uneven. The design aimed to achieve a maximum target weight of $35 \mathrm{~kg}$ to ease off-shore deployment with a maximum of two human operators. The mooring chain link size can vary according to the place, application, load capacity etc. For design purposes, a drawing of the morning chain under investigation in this study is illustrated in Figure 2. 


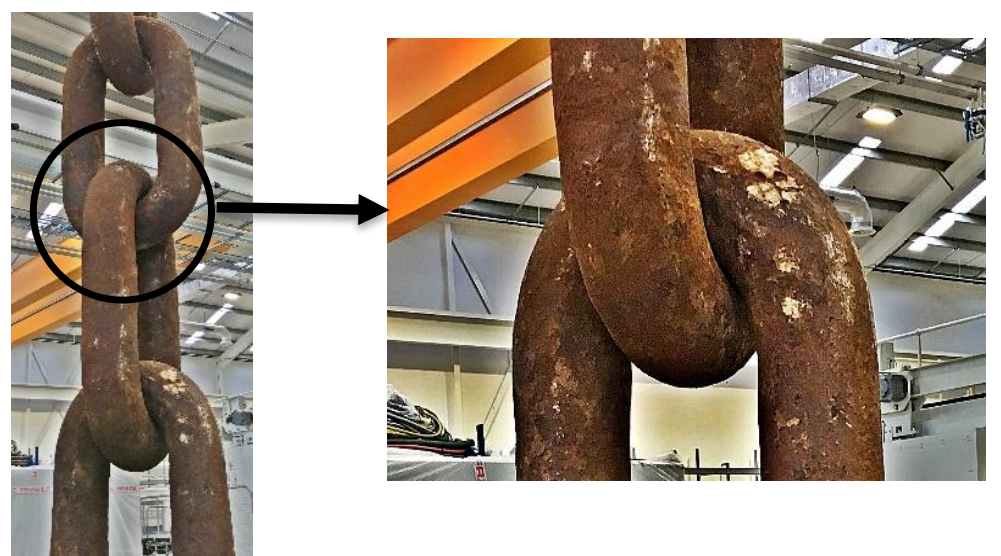

Figure 1: Mooring chain's uneven, rusted surface (sample image)

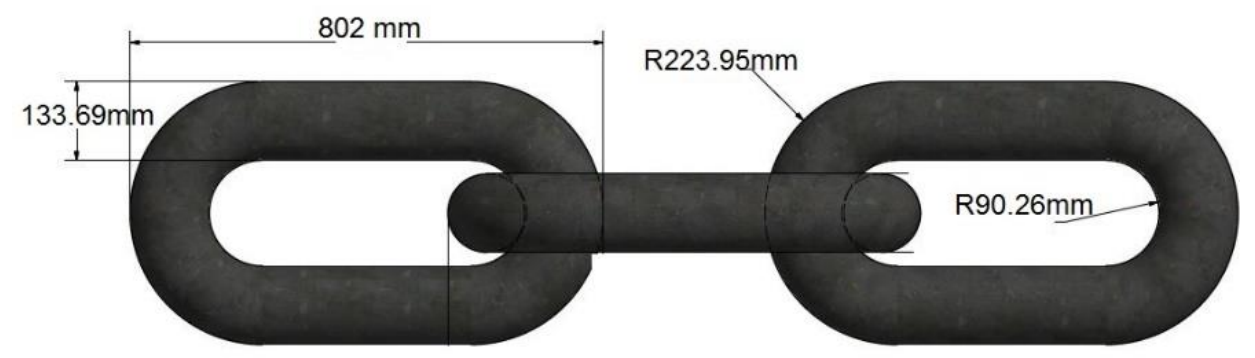

Figure 2: Drawing of the mooring chain used in this investigation

\subsection{Concept of the climbing robot}

The locomotion idea is to use two set of tracked-wheel units that are kept in an orthogonal position to match the orthogonal links of a mooring chain. One tracked-wheel unit moves on one chain link whilst the other moves on to an adjacent orthogonal chain link (refer Figure 3). Therefore, each orthogonal set of tracked-wheel units enable the robot to move continuously along the chain. Units A and D (refer Figure 4-a) represent parallel wheels that move on parallel tracks of a link on one side, while units $\mathrm{B}$ and $\mathrm{C}$ represent parallel wheels that move on parallel tracks on the orthogonal links. During the climbing process, A- D \& B-C tracked-wheel units engage with the relevant chain surfaces to support the motion as illustrated in Figure 4-b. Permanent magnets are considered due to their zeroenergy consumption and because of the amphibious nature of mooring chains. Positioning of the adhesion module on uncertain surfaces is minimised due to the passive adhesion quality of the permanent magnets. 
(a)

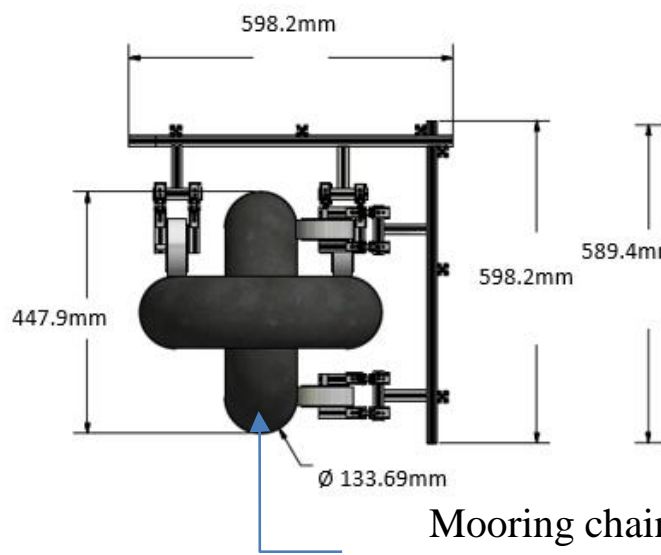

(b)

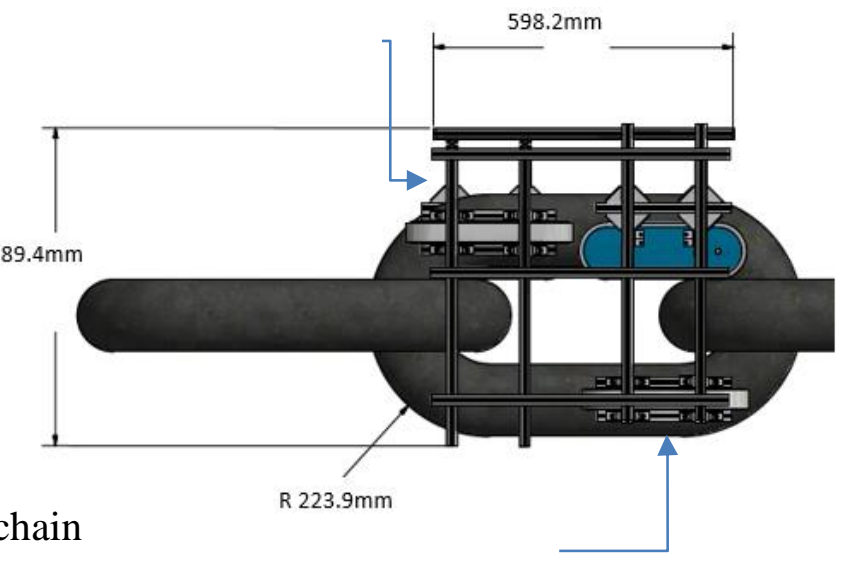

Figure 3: Proposed robot dimensions with the chain. (a) \&(b) illustrates the conceptual design of the platform and tracked wheel positions. (a) illustrates orthogonal tracked-wheel placement (cross section view)

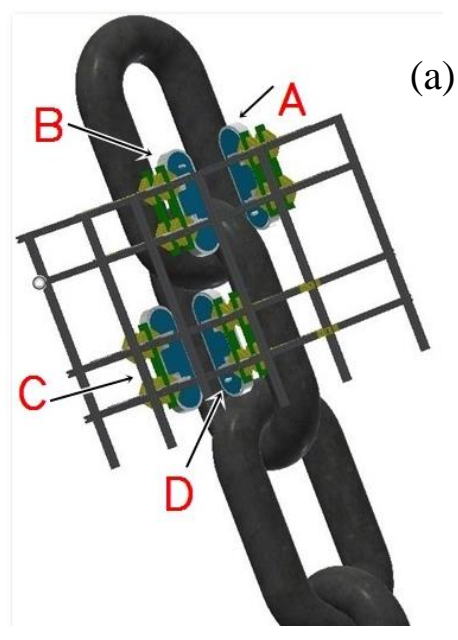

(a)

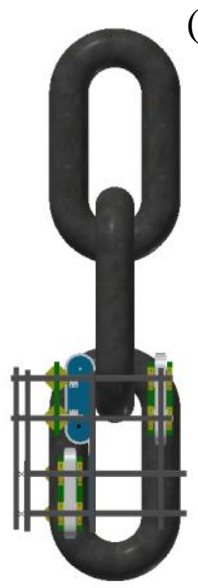

Stage 1 (b)

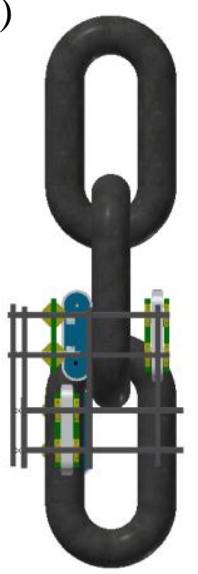

Stage 2

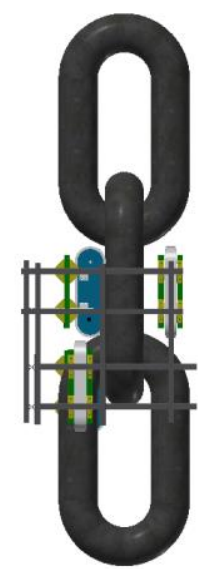

Stage 3

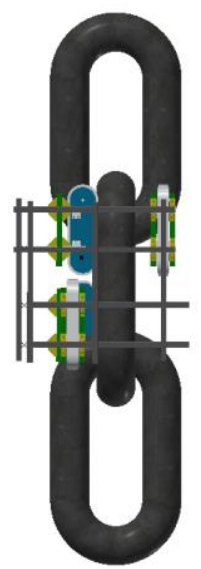

Stage 4

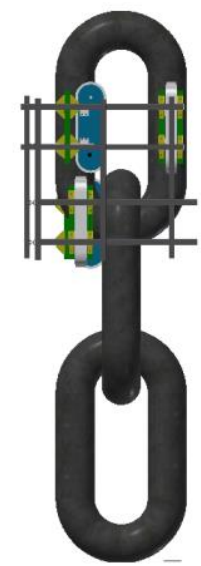

Stage 5

Figure 4: Conceptual design explanation (a) tracked-wheel unit placement. (b) robot climbing sequence

\subsection{Design of the robot frame}

Easy deployment ability and retrievability is considered during the robot frame design phase. A structure/frame that needs to be deployed around a chain link is not practical due to the in-situ mooring chain conditions. Therefore, a light weight " $L$ " shaped frame which can be easily put on to the chain link is designed and analysed. The CAD design presented in Figure 3-a is designed to hold orthogonal crawlers that fit on to a specified chain link (Figure 1). Un-enclosed characteristic of the "L" shaped design allows robot operators to easily deploy/retrieve the robot on/off the chain. According to the climbing concept, at a given point two tracked-wheel units are attached to the chain whilst the other two are 
suspended in air. It was necessary to understand the displacement behaviour of unattached tracked-wheel units in 3D space. If the displacement of the unattached units is significant (which can disturb the linear trajectory of motion), vertical climbing can be disturbed because they need to be placed on the next chain surface. Therefore, a Finite Element Analysis (FEA) was conducted to understand the displacement behaviour of unattached tracked wheel units.

FEA study 01- Static structural module in ANSYS workbench was used in this study with a mesh of maximum element size of $20 \mathrm{~mm}$ and minimum element size of $0.1 \mathrm{~mm}$. Material properties assumed for the study are in table 1. The layout presented in Figure 5(a) was used in the study under gravity forces. The tracked-wheel unit displacements in 3D space are presented in Figure 5(b, c \& d). According to the study, maximum displacement occurred along the $\mathrm{x}$ axis (refer to Figure 5c) which is $0.394 \mathrm{~mm}$ and it is relatively low when compared to the width of the chain link $(\approx 133 \mathrm{~mm})$.
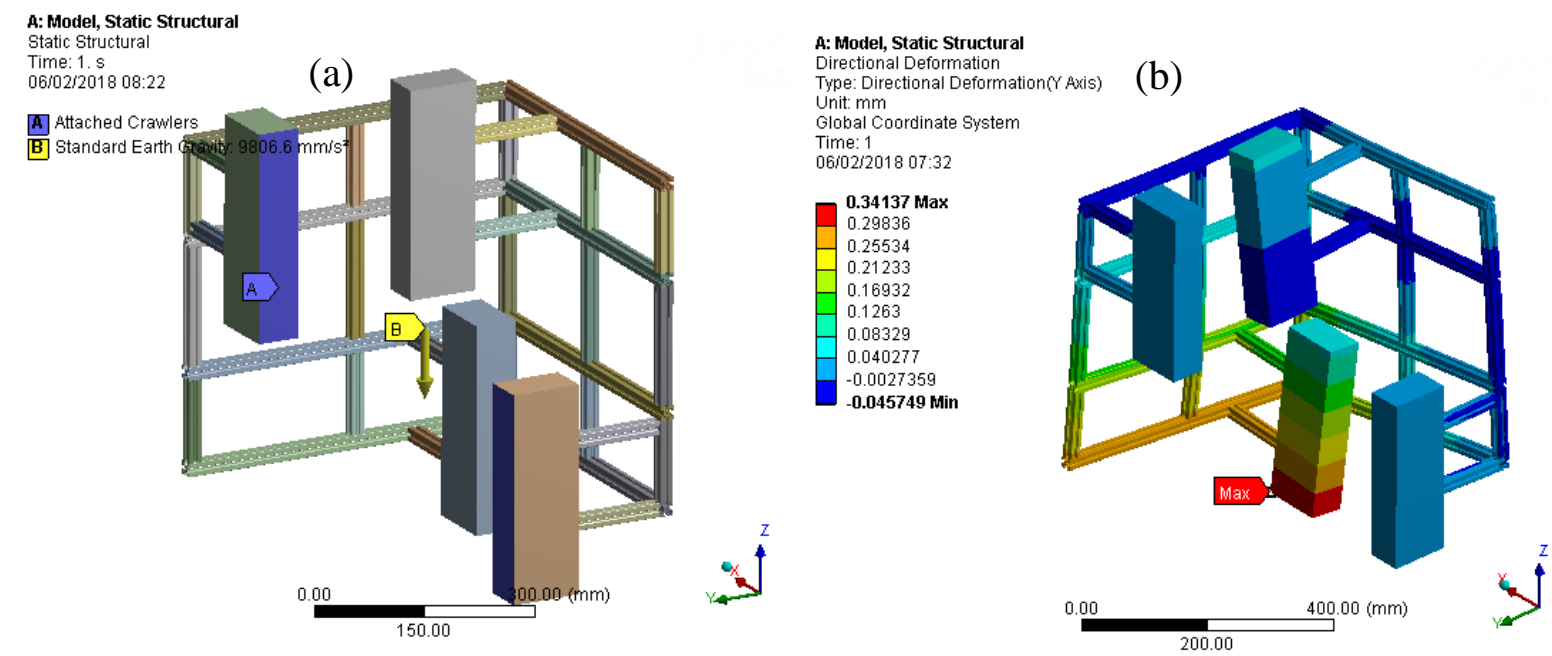

(c)

A: Model, Static Structural
Directional Deformation Type: Directional Deformation $(\times$ Axis $)$

Unit: $\mathrm{mm}$

Unit $\mathrm{mm}$
Global Coordinate System

Time: 1

06/02/2018 07:33

0.39402 max

0.34525

0.29648

0.24772
-0.19895

0.15019

0.10142

0.052655

0.0038892

-0.044877 Min

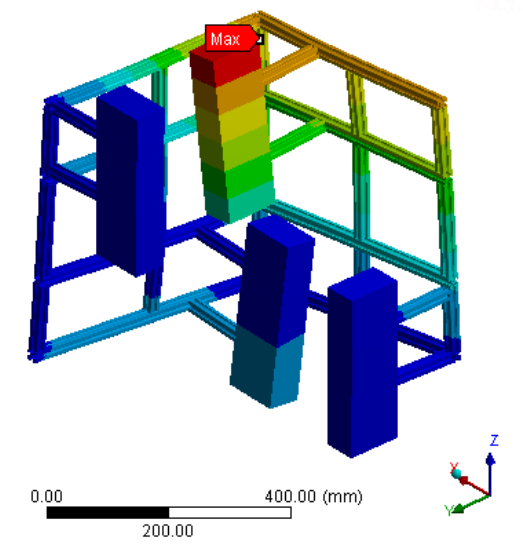

A: Model, Static Structural Directional Deformation Directional Deformation
Type: Directional Deformation (Z Axis) Unit: $\mathrm{mm}$ Global Coordinate System Time: 1

06/02/2018 07:35

$5.8983 \mathrm{e}-5 \mathrm{Max}$

$-0.047263$

$-0.094585$

$-0.14191$

$-0.18923$

-0.23655
-0.28387

-0.28387
-0.33119

-0.33119
-0.37852

0.42584 Min

(d)

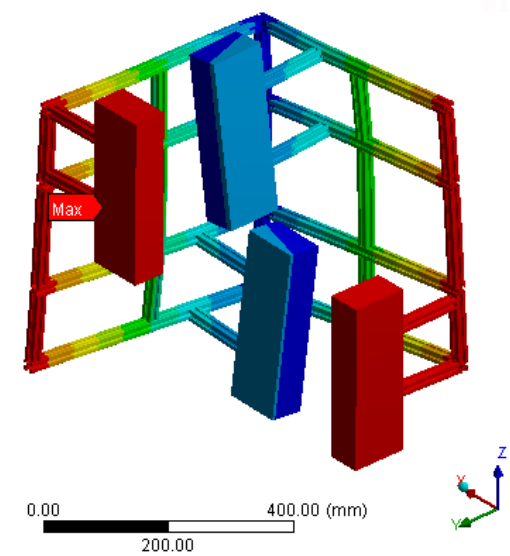

Figure 5: Structural deformation analysis: No payload. (a) model layout, (b) y axis deformation, (c) $\mathrm{x}$ axis deformation and (d) $\mathrm{z}$ axis deformation 
The structural health monitoring of mooring chains is the main objective of this robotic platform. Therefore, it is vital to understand the behaviour of the frame when carrying a payload. The payload is assumed to be the weight of the NDT instrumentation such as ultrasonic probe/probe manipulator, camera, etc. A payload of $100 \mathrm{~N}$ is equally distributed and added to both sides of the frame (refer to Figure 6-a: layout of the model).

FEA study 02- Static structural module in ANSYS workbench was used in this study. Material properties assumed for the study are tabulated in table 1 . The layout presented in Figure 6-a was used in the study. Tracked-wheel unit displacements in 3D space are presented in Figure 6(b, c \& d). According to the study, maximum displacement occurred along the $\mathrm{x}$ axis (refer to Figure 6-c). The displacement monitored is $0.814 \mathrm{~mm}$ and this is still relatively low when compared to the width of the chain link $(\approx 133 \mathrm{~mm})$. Therefore, it is possible to conclude that the proposed "L" shaped frame/ tracked wheel unit displacements are significantly low and the impact of tracked-wheel orientation due to the structural displacement is negligible.

(a)

A: Model, Static Structural

Static Structura

Time: 1 . 5
$06 / 02 / 201807: 59$

A Attached Crawlers

A Attached Crawlers

C] NDT load1: $50 . N$
D. NDT load2: 50 . N

(c)

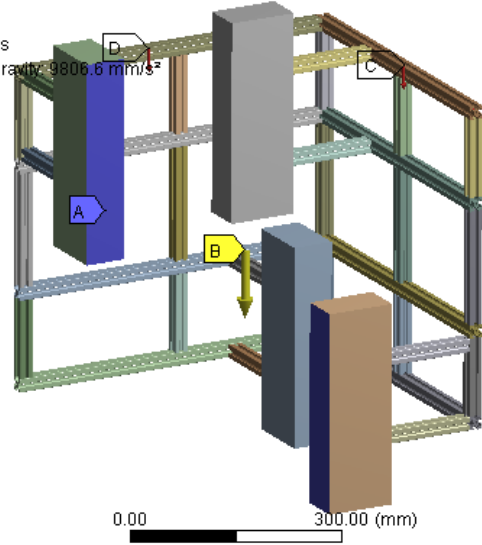

A: Model, Static Structural

Directional Deformation
Type: Directional Deformation $(x$ Axis

Type: Direction
Unit: $\mathrm{mm}$

Unit: $\mathrm{mm}$
Global Coordinate System

Time: 1 06/02/2018 07:55

$\mathbf{0 . 8 1 4 9 7}$ Max

$\square \begin{aligned} & \mathbf{0 . 8 1 4 9 7} \\ & 0.70562 \\ & 0.59627\end{aligned}$

0.48692
-0.37757
0.26822

0.37757
-0.26822
0.15897

0.15887
0.049525

0.049525
-0.059824

-0.16917 Min

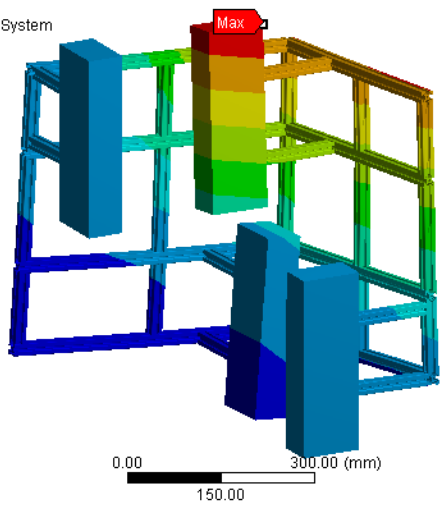

(b)

\section{A: Model, Static Structural \\ Directional Deformation}

Type: Directional Deformation( $\mathrm{Axis}$ )

Unit: $\mathrm{mm}$

Global Coordinate System

Time: 1 06/02/2018 07:57

0.70192 Max

0.60713
0.51234

0.41756

0.32277

0.22798

0.13319
0.038407

-0.05638
$-\mathbf{0 . 1 5 1 1 7}$ Min

(d)
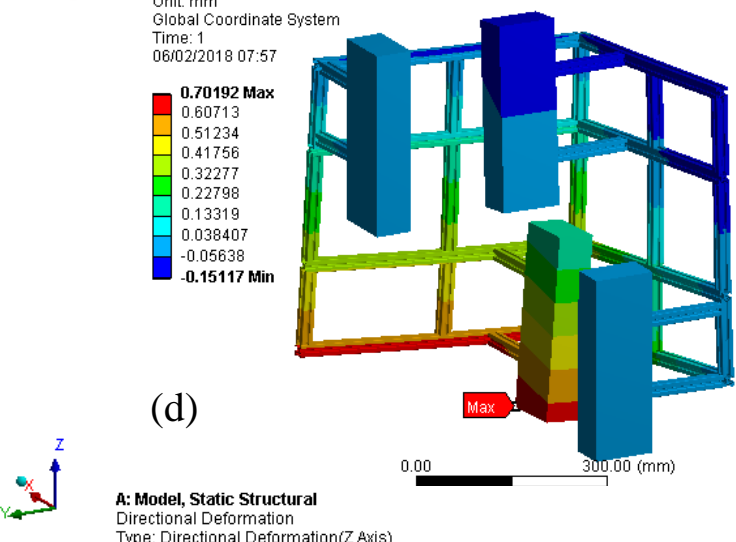

A: Model, Static Structural
Directional Deformation

Type: Directional Deformation(Z Axis)

Global Coordinate System

Time: 1 06/02/2018 07:53

$\square_{-0.099606}^{\mathbf{0 . 0 0 0 1 5 4 5 6} \max }$

$-0.19937$

$-0.29913$

$-0.39889$

$-0.49865$

-0.59841
-0.69817

-0.69817
-0.79793

-0.89769 Min
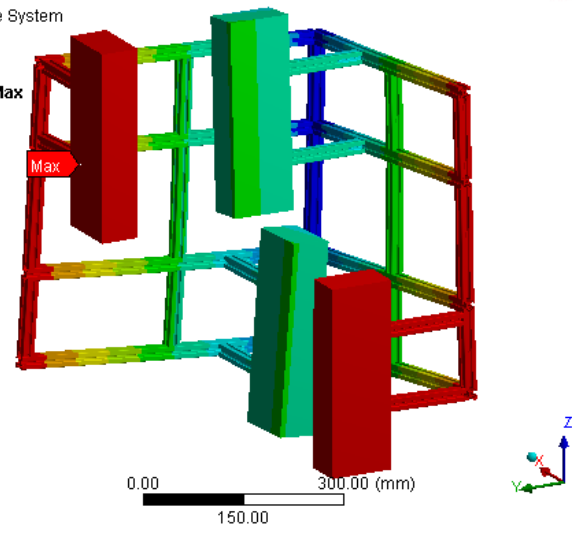

Figure 6: Structural deformation analysis: 100N payload. (a) model layout, (b) y axis deformation, (c) $\mathrm{x}$ axis deformation, and (d) $\mathrm{z}$ axis deformation 
Table 1: Frame design / modelling parameters

\begin{tabular}{|l|l|}
\hline Parameter & Parameter value \\
\hline Material & EN AC-51400 Cast Aluminium \\
\hline Density & $2.7 \mathrm{~g} / \mathrm{cm}^{3}$ \\
\hline Young's Modulus & $70 \mathrm{GPa}$ \\
\hline Tensile Strength: Ultimate & $200 \mathrm{MPa}$ \\
\hline Tensile Strength: Yield & $120 \mathrm{Mpa}$ \\
\hline Poisson's Ratio & 0.33 \\
\hline
\end{tabular}

\subsection{Motor payload requirements}

Due to the orthogonal placement of crawler units (tracked wheels), each of them is powered with an external motor and a gearbox. The required torque calculation [ $\left.\mathrm{T}_{\mathrm{mot}}\right]$ to drive the robot structure up along the chain link against the resultant structural downward forces and magnet adhesion forces is previously studied in the literature [15] and can be calculated as follows (Eq.01).

$\mathrm{T}_{\mathrm{mot}} \geq[$ Resultant weight $\times$ Distance to surface $]+[$ Force due to magnet $\times$ Radius $] \quad$ Eq.01

Eq.01 can be adopted for Figure 7 as follows;

$\mathrm{T}_{\mathrm{mot}} \geq \mathrm{W} \times\left\{\left(\mathrm{r}_{1}-\mathrm{r}_{2}\right) \times[(\mathrm{W}-\mathrm{Wc}) / \mathrm{W}]+\mathrm{r}_{2}\right\}+\left(\mu \mathrm{F}_{\mathrm{m}} \times \mathrm{R}\right)$

Required speed of the robotic platform is calculated by using Eq.03

$\mathrm{S}_{\mathrm{r}}=\mathrm{RPM}_{\mathrm{g}+\mathrm{m}} \times[2 \pi \times \mathrm{R}]$

where, $\mathrm{RPM}_{\mathrm{g}+\mathrm{m}}$, is the RPM of the gearbox + motor combination, $\mathrm{R}$ is the effective radius of the track-wheel, and $S_{\mathrm{r}}$ is the Net speed (per minute) of the robot. 
According to the orthogonal tracked-wheel concept of climbing, at least two sets of tracked-wheel units contribute to the motion at a given point. Therefore, each crawler should be capable of delivering half of the torque which is calculated in equation 2 (approximately $16 \mathrm{Nm}$ ). Speed of the robot is calculated as $42 \mathrm{~cm} / \mathrm{min}$. Inspection methods are not presented at this stage of the research but the speed of the robot needs to be allocated according to NDT inspection requirements.

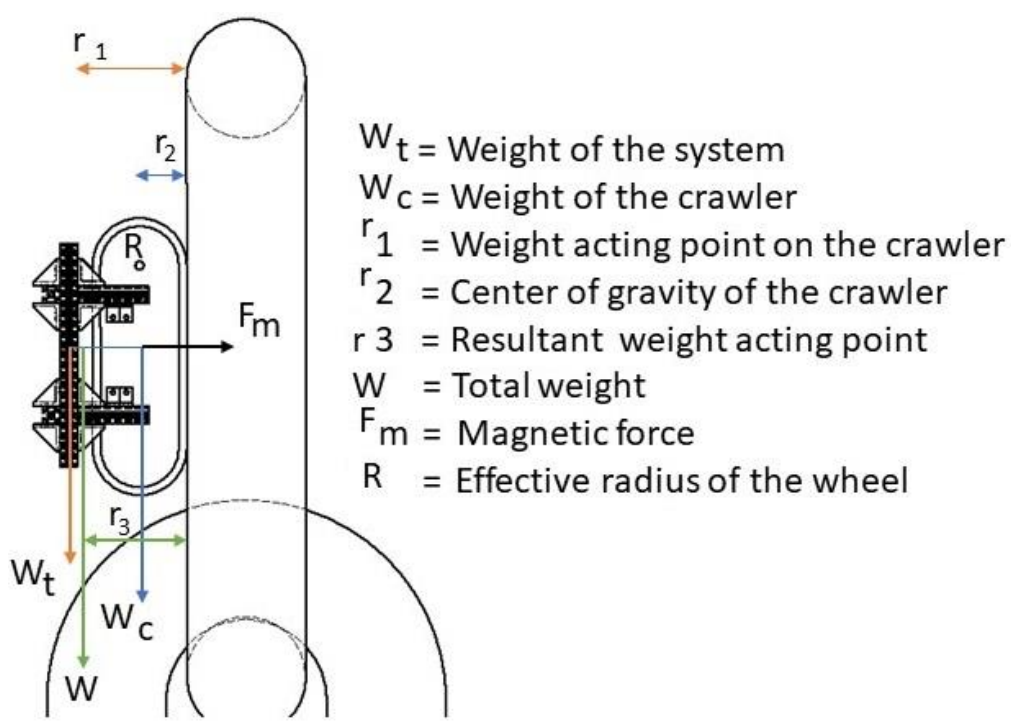

Figure 7: Tracked-wheel force diagram

\subsection{Design of the tracked wheel unit (locomotion unit)}

Selection of locomotion method was carried out with the information provided in previous research [15]. Due to harsh operational conditions (i.e. rough, curved, uneven, amphibious nature) of the mooring chain surfaces, it is convenient to use a track wheeled locomotion mechanism. The tracked wheel model was selected because passive track adaptation according to uneven surfaces gives an additional traction advantage, payload capacity is reasonably high and control complexity is comparatively less. CAD models of the tracked modules are presented in Figure 8. In order to avoid the effect of parallel misalignments of the chain links (slight differences in angles related to parallel link tracks), it is necessary to keep the total length of the crawler track less than the gap between two parallel links. Therefore, the total length of a crawler has been kept less than the gap $(<355 \mathrm{~mm})$. 

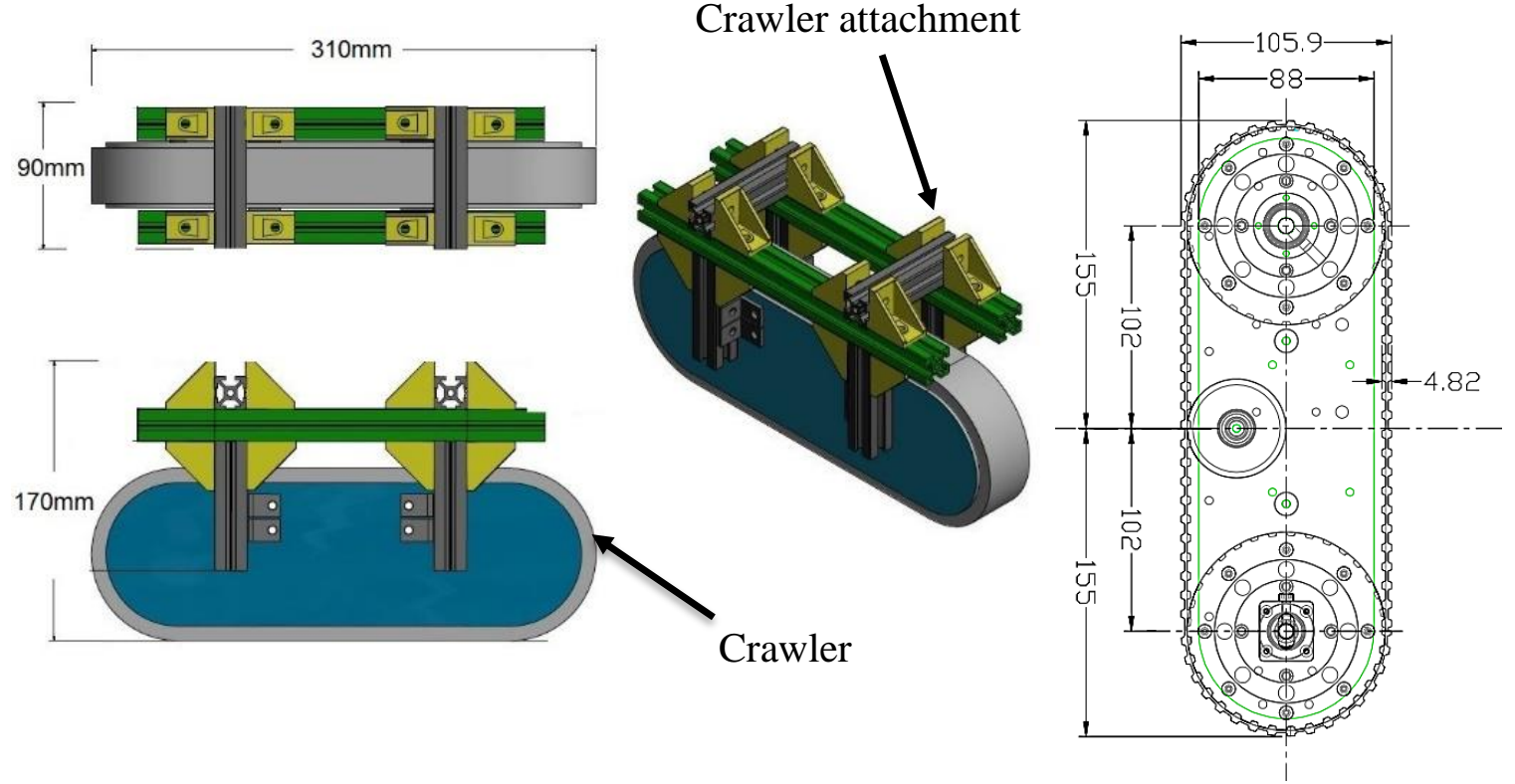

Figure 8: Tracked-wheel design and internal dimensions inside the tracked-wheel unit

\subsection{Optimisation of the adhesion module}

Mooring chain links are made from thick iron rods which are ideal surfaces for a permanent magnetic adhesion system. Magnetic adhesion is the most suitable adhesion mechanism when the surface is uneven, curved and ferromagnetic, because of its non-contact and passive adhesion qualities. The required adhesion force, $\mathrm{Fa}$ can be calculated by using previously studied equation Eq.04 [16].

$\mathrm{Fa} \geq \frac{\mathrm{W} \times \sin (\alpha)}{\mu}-\mathrm{w} \times \cos (\alpha)$

Eq.04

where, the robot's parameters are weight $(\mathrm{W})$, coefficient of friction $(\mu)$, and vertical plane's inclination $(\alpha)$. Net weight of the robot is $\sim 191.23 \mathrm{~N}$.

According to Eq.04, required minimum total adhesion force is calculated as $382.46 \mathrm{~N}$. Two track-wheel units support the movement; therefore, each tracked wheel unit should be able to provide a minimum adhesion force of $191.23 \mathrm{~N}$. Using a back-plate to minimize the magnetic flux leakage which leads to focus more magnetic flux towards the required area was studied in the literature [16-18]. The same technique is adopted in this research to calculate a sufficient adhesion force. It is required to keep the permanent magnets tangential and perpendicular to the chain surface to get an optimum adhesion force. Therefore, magnets are inserted in the crawler as illustrated in Figure 12. In the present study, magnets-to-chain-surface air gap is $9 \mathrm{~mm}$ due to the mechanical clearances of the tracked-wheel unit. 
FEA study: Stationary simulation was conducted in COMSOL Multiphysics with use of "Magnet field, no current(MFNC)" module. Free tetrahedral mesh was created with maximum element size of $10 \mathrm{~mm}$ and minimum element size $0.1 \mathrm{~mm}$. Data presented in table 2 was used in the numerical modelling. Figure 9-d CAD model was designed according to the schematic presented in Figure 9(a,b,c). A $219.16 \mathrm{~N}$ force was produced by the experimental magnet (N52, neodymium) arrangement. Figure 10, illustrates simulation results of focused magnet flux lines when the back plate is present and unfocused flux lines when back plate is not in use. 30\%(approximately) increase of adhesion force was obtained by introducing the backplate.

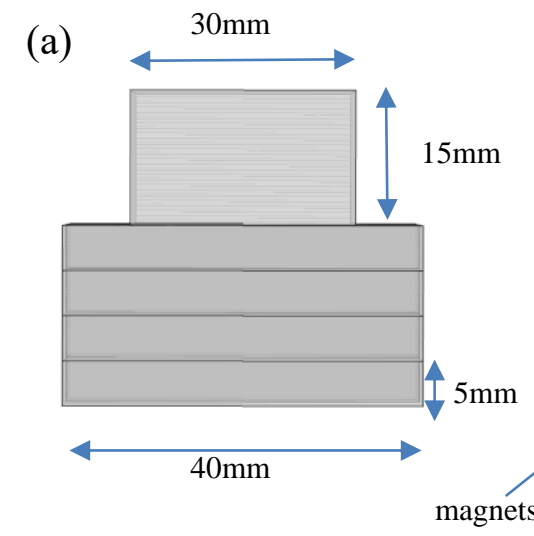

(b)
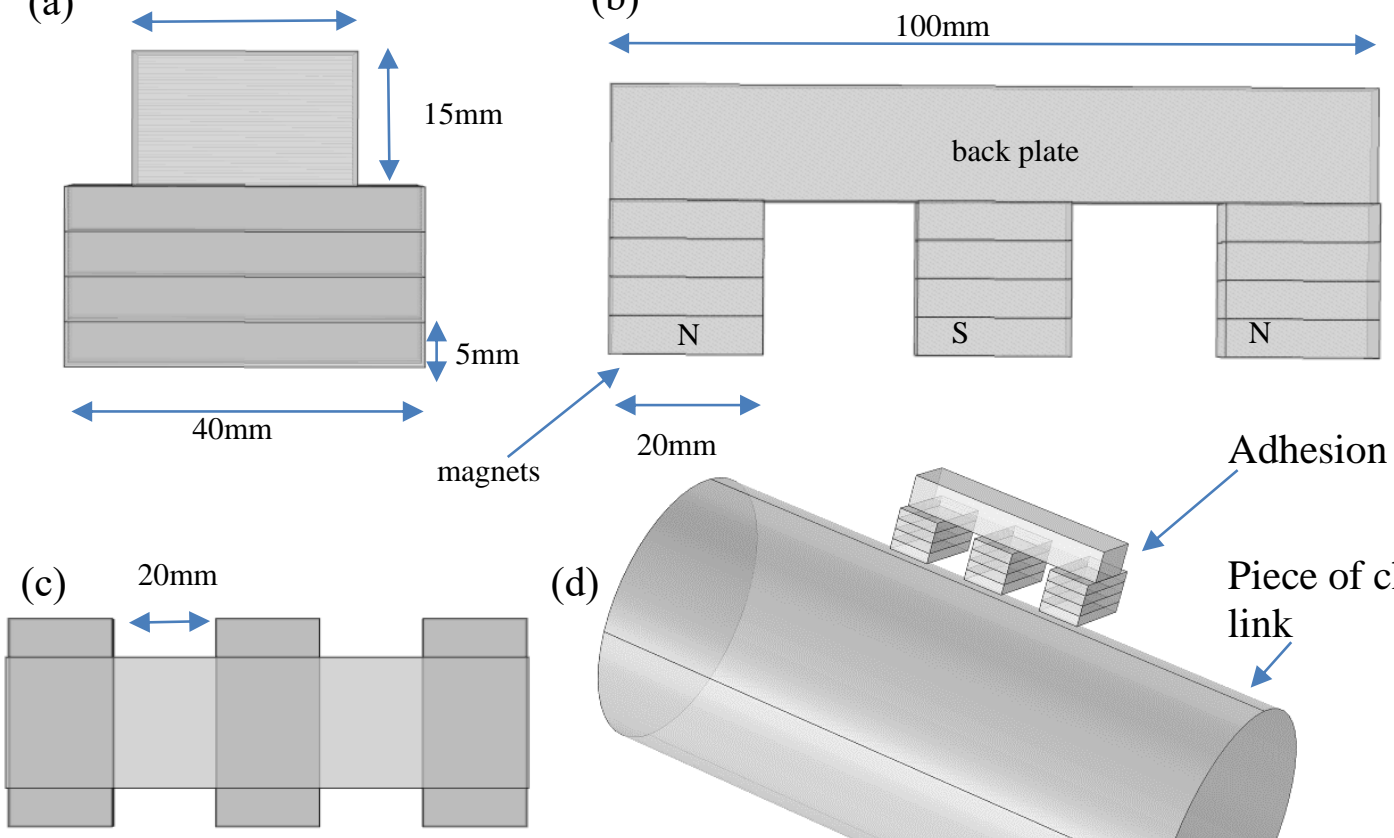

(d)
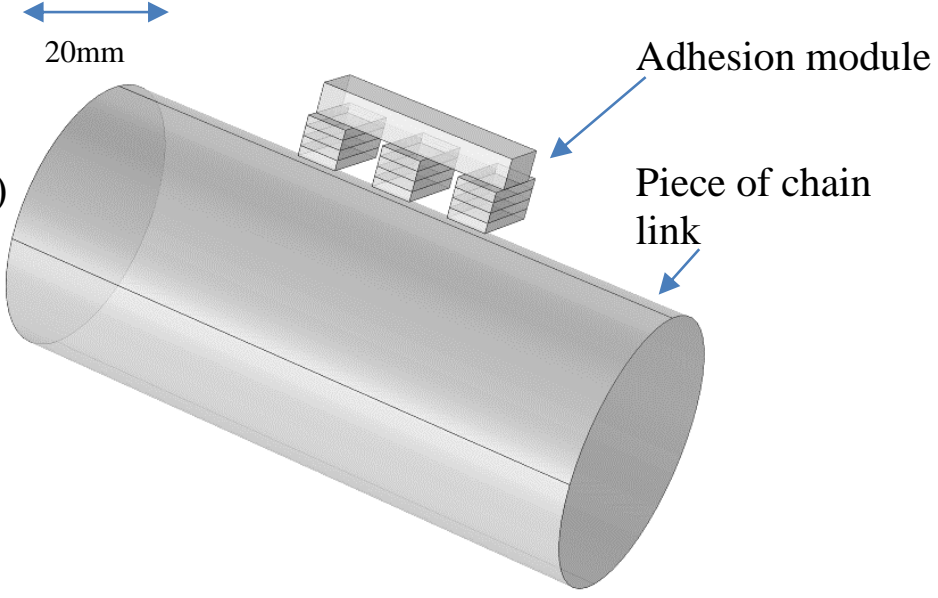

Figure 9: Design of the magnetic adhesion module. (a, b \&c) schematic of the magnet backplate design. (d) numerical modelling layout (COMSOL) 

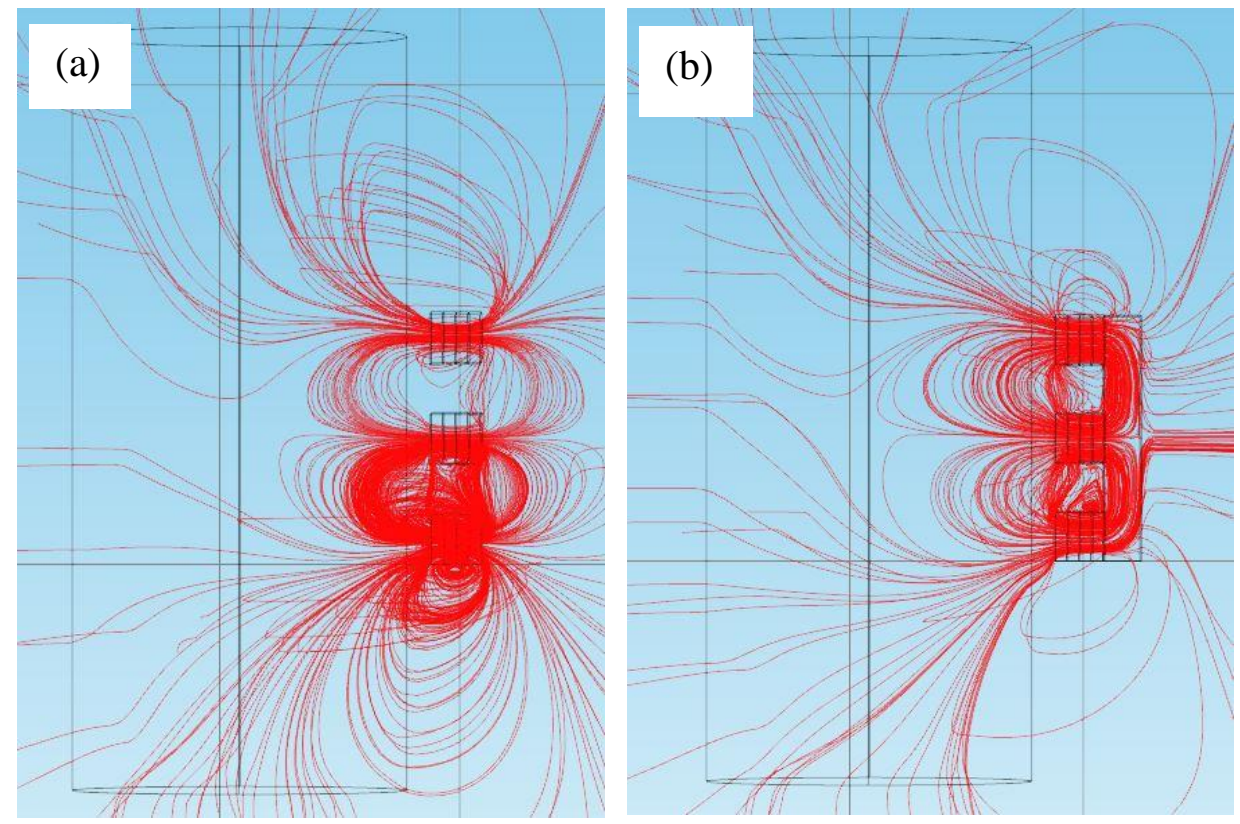

Figure 10: Numerical results of the magnetic flux distribution (a) unfocused magnetic flux lines when there is no back plate (b) flux line concentration towards chain surface when the back plate is introduced

Table 2: Modelling parameters

\begin{tabular}{|c|c|}
\hline Parameter & Parameter value \\
\hline Magnet Relative permeability & 1.05 \\
\hline Residual Flux Density (Br) & $1.45 \mathrm{~T}$ \\
\hline Magnet size /back plate size & $\begin{array}{l}\mathrm{L} 40 \mathrm{~mm}, \mathrm{~W} 20 \mathrm{~mm}, \mathrm{H} 5 \mathrm{~mm} / \mathrm{L} 100 \mathrm{~mm}, \mathrm{H} \\
15 \mathrm{~mm} \text {, W } 40 \mathrm{~mm}\end{array}$ \\
\hline Iron relative permeability & 4000 \\
\hline Coefficient of friction & 0.5 (used during the required force calculation) \\
\hline
\end{tabular}




\section{Prototype}

\subsection{Prototype and assembly of crawler unit, adhesion module and "L" frame}

As explained in the previous section, a prototype of the proposed tracked-wheel was constructed (refer Figure 11-12). Figure 11 illustrates the mechanical components of the prototyped tracked-wheel unit. Then the adhesion module was inserted (refer figure 12-a). There are small changes in the air gap between magnet-chain surface (due to the uneven surface of mooring chains). This leads to a sudden increase/decrease of adhesion force. Therefore, small, support wheels were introduced in between the magnets to keep the air gap steady during the entire motion (refer Figure 12-b). The support wheel and crawler was made of aluminium to avoid any interference with magnets. Small cuts were introduced to the crawler to keep the magnets in place as illustrated in Figure 12-b (it is important to keep a constant air gap between two magnets). The " $L$ " shaped main frame was prototyped and the four tracked-wheel units were attached to the frame (refer Figure 13). Additional $10 \mathrm{~cm}$ of aluminium extrusions were used during the prototyping for mechanical and practical advantages (i.e. to handle the robot during the experiment, lift the main frame above the ground level, etc.,).
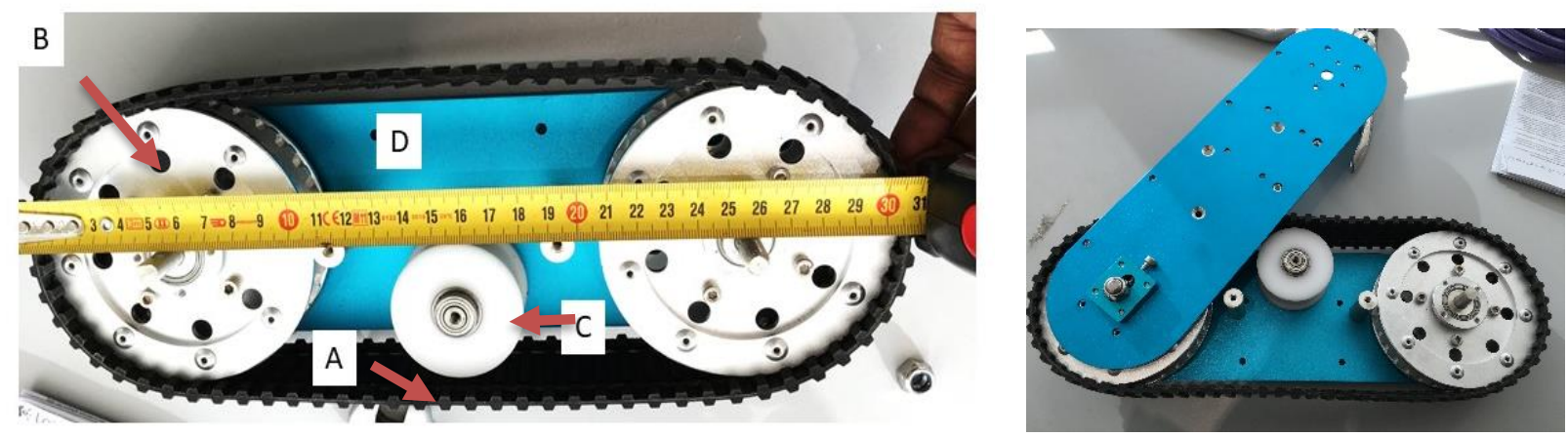

A - Rubber track, B - Aluminum wheel, C - Tension wheel, D - Aluminum cover

Figure 11: Mechanical parts of the prototyped tracked-wheel module / inside view 


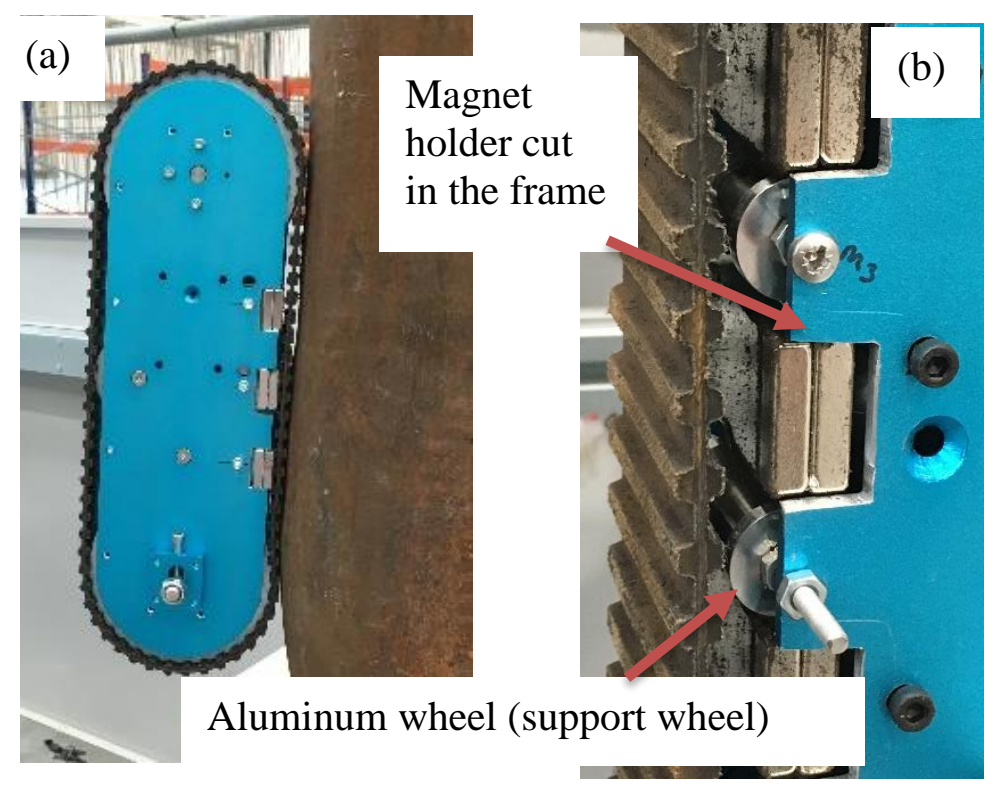

Figure 12: Prototyped tracked-wheel unit. a- magnet inserted tracked wheel unit. b small cuts in the frame and aluminum support wheels.

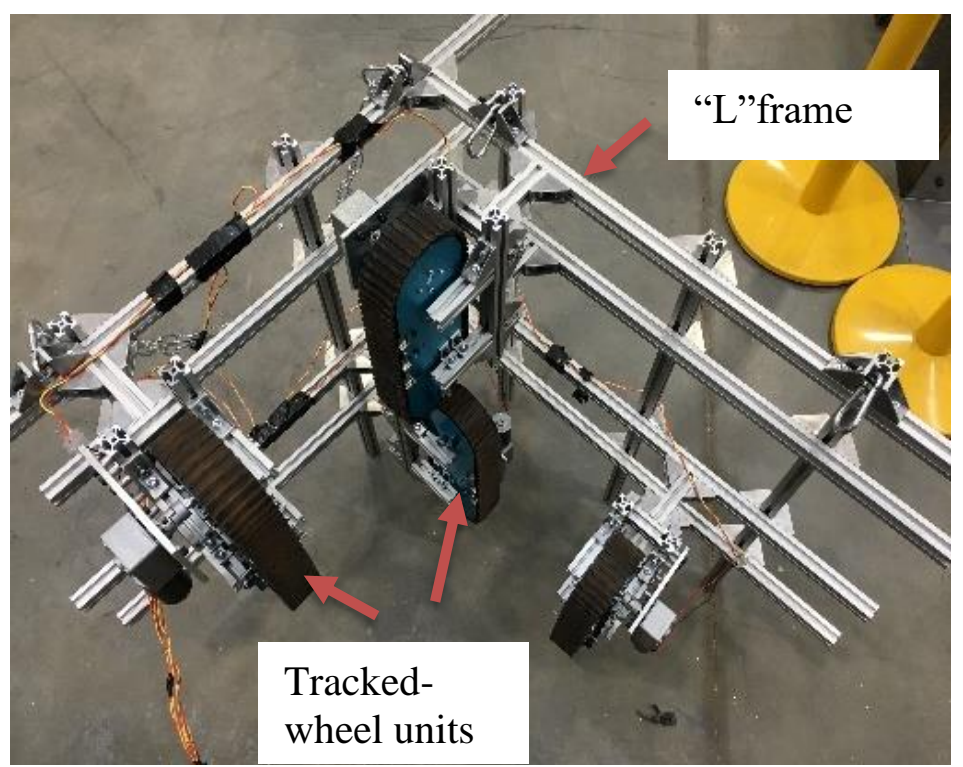

Figure 13: Prototyped L shape frame with tracked-wheel units 


\subsection{Motor attachment and control unit}

Each crawler unit was equipped with a brushless DC motor and a suitable worm gearbox to supply the calculated/required torque. To save the space between orthogonal chain links and crawlers, each motor was attached to the crawler with a $90^{\circ}$ attachment (refer Figure 14) The aim of this study was to establish the basic principle of lightweight and fast tracked-wheel based robot solution. Therefore, the basic flow chart operation described in Figure 15 was used to drive the robot platform along the mooring chain.
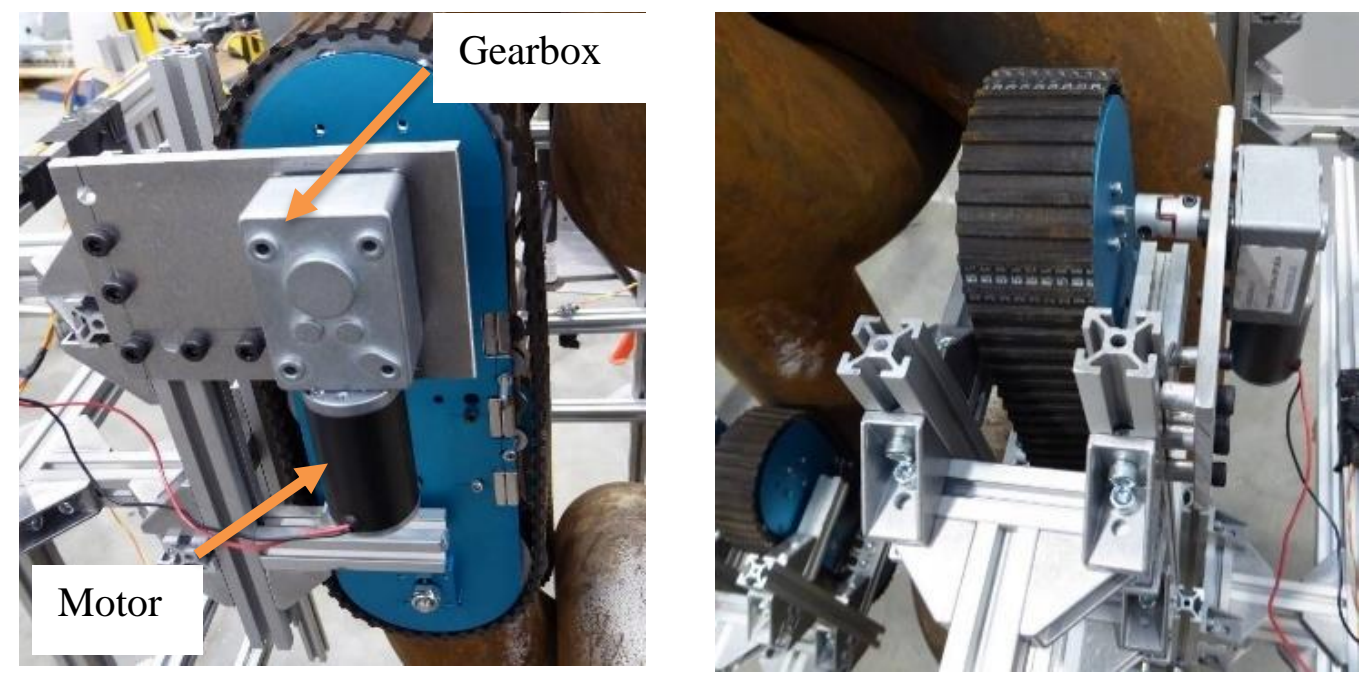

Figure 14: Motor and Gearbox attachment and placement on the robot

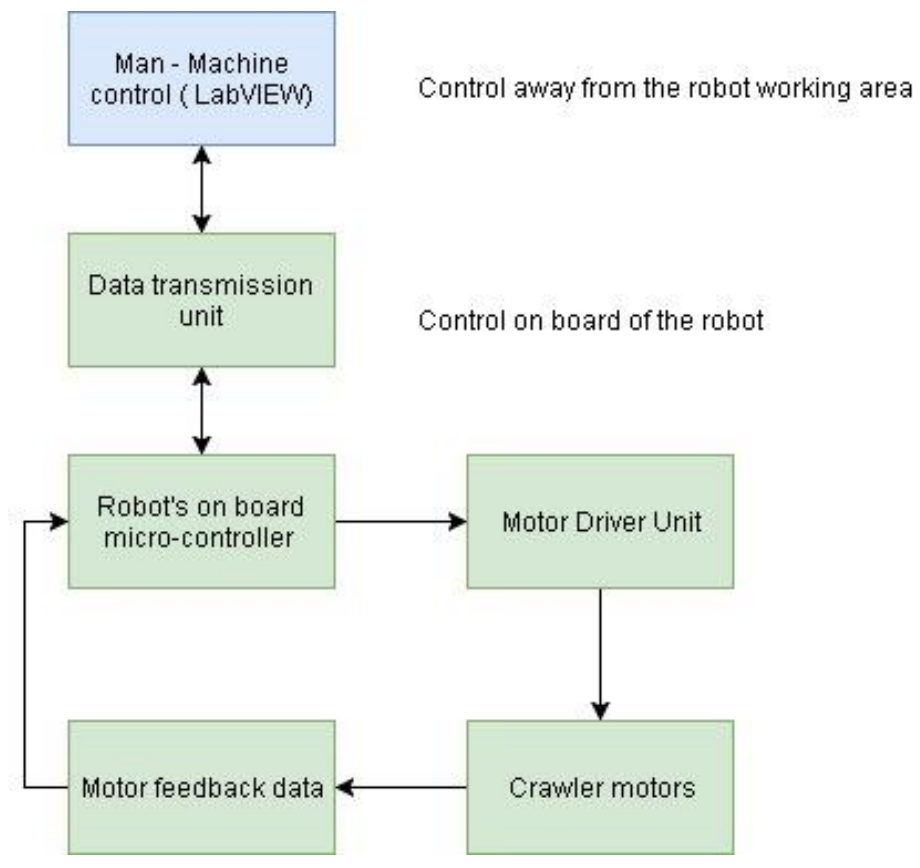

Figure 15: Control diagram of the robot 


\section{Testing and Validation}

\subsection{Adhesion forces validation test-rig}

During the design and numerical modelling of the adhesion modules, a magnet setup was proposed. The test-rig in Figure 17 was used to validate the magnetic adhesion results which were simulated in the FEA study. The frame and magnet holding plates were made with (3-5 mm) carbon fibre and aluminium plates. Magnets were attached to an aluminium plate with a free movement towards the direction of magnetic forces and the plate was kept on a set of four load cells. To enhance the accuracy in reading, load cells were configured as a "Wheatstone bridge". The amplified signal of the load cell was connected to a microcontroller to get readings. Aluminium spacers were introduced to maintain the same air gap as in the FEA simulation. During the preparation of the test rig, pre-calibrated weights form $1 \mathrm{~N}$ to $70 \mathrm{~N}$ were used to calibrate the reading scale. Experimental magnet sets in Figure 16 were tested in the test-rig and forces recorded in Table 3. Recorded experimental adhesion results and FEA results have good agreement and the maximum variation is $6.07 \mathrm{~N}$. Change of air gap distances $( \pm 0.5 \mathrm{~mm})$ while setting up the test- rig and sensitivity of the loadcells ( $0.2 \%$ manufacturing error in the sensor) are possible factors for the error between FEA and experimental. According to the results, it is possible to accept the validity of FEA study and force calculations.

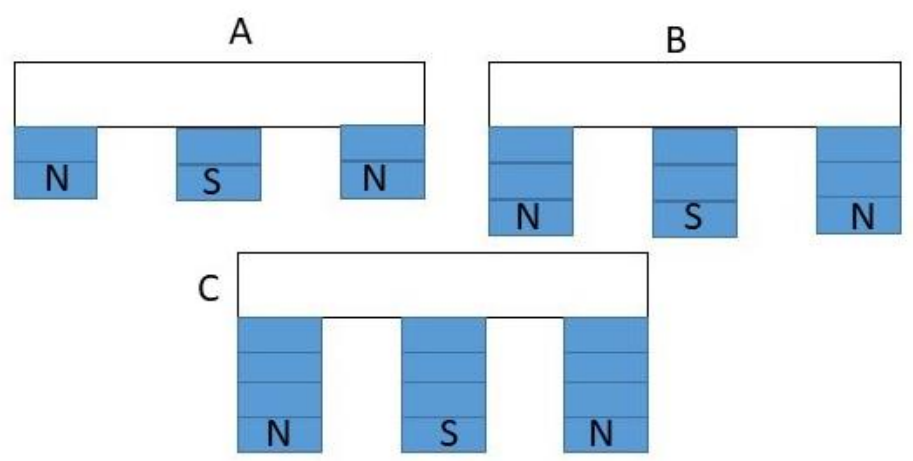

Figure 16: experimental magnet adhesion modules (used in Figure 17 test rig) 
(a)

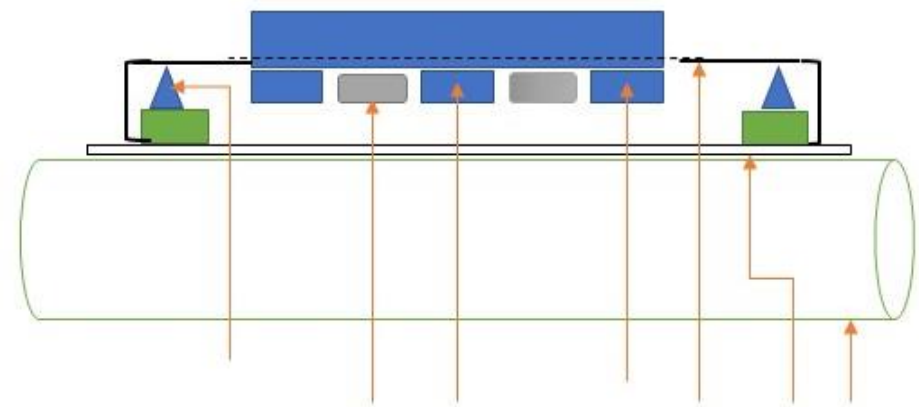

(b) $\quad E \quad G \quad F \quad$ D $\quad C \quad B \quad A$
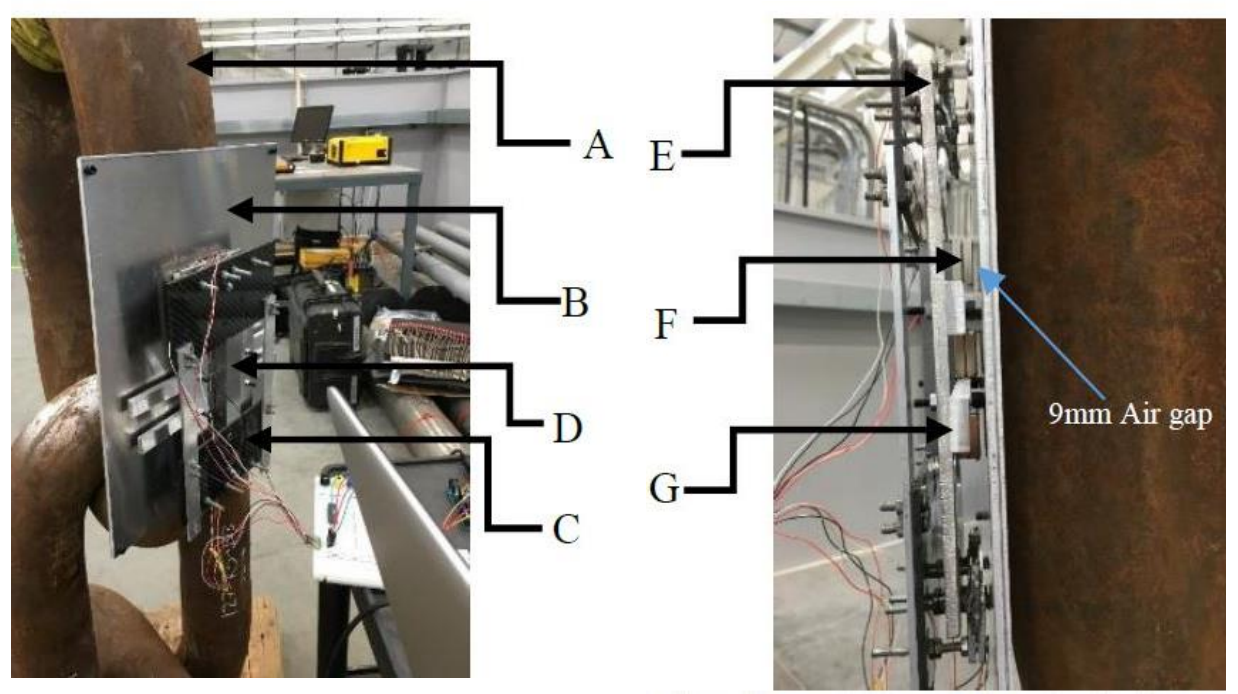

A-Mooring chain, B- Base Plate C-Carbon fibre test rig, D-Iron Back plate and magnets, E-Load cells, F-Magnets, G-Spacers

Figure 17: Magnetic adhesion validation test rig. (a) Schematic of the test-rig, (b) test-rig used in the experiment 
Table 3: Simulation vs experimental results (magnet set -refer Fig 16)

\begin{tabular}{|c|c|c|c|}
\hline $\begin{array}{c}\text { Studied } \\
\text { magnet } \\
\text { arrangement }\end{array}$ & $\begin{array}{c}\text { Numerical } \\
\text { Modelling Results }\end{array}$ & $\begin{array}{c}\text { Experimental } \\
\text { Results }\end{array}$ & *Error \% \\
\hline A & $164.95 \mathrm{~N}$ & $155.504 \mathrm{~N}$ & $-6.07 \%$ \\
\hline $\mathrm{B}$ & $182.17 \mathrm{~N}$ & $185.35 \mathrm{~N}$ & $1.72 \%$ \\
\hline $\mathrm{C}$ & $219.16 \mathrm{~N}$ & $216.60 \mathrm{~N}$ & $-1.18 \%$ \\
\hline
\end{tabular}

$*$ Error calculation $=[($ Experimental - Numerical $) /$ Experimental $] \times 100$

\subsection{Laboratory climbing sequence test}

The climbing sequence illustrated in Figure 18 was recorded from the laboratory experiment trial. The crawler robot was placed on the mooring chain and up/down movement was inspected. The experimental trial was conducted in an industrial environment. Therefore, an additional safety cable was used to enhance the safety (internal laboratory safety regulation). The robot was able to attach to the chain and climb the mooring chain by making transitions between chain clinks.

In the present stage of the research, the mooring chain inspection mechanism has not been included, therefore the above climbing test is with the robot's own weight. A stability check was performed with external payloads (Figure 19) to check the adhesion capability of the design. According to the experimental results, the robot stayed attached to the chain link surface with up to $50 \mathrm{~N}$ of external force (all the safety cables were released during in the stability test experiment). 


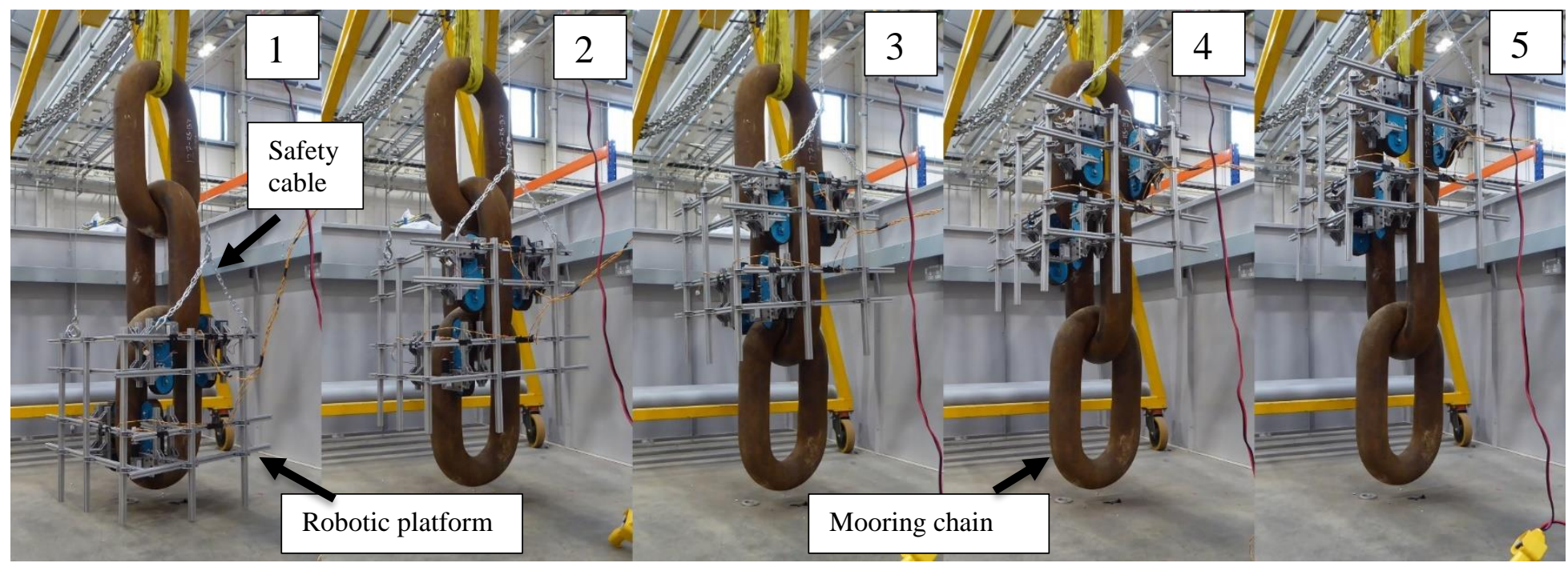

Figure 18: Robot platform climbing experiment

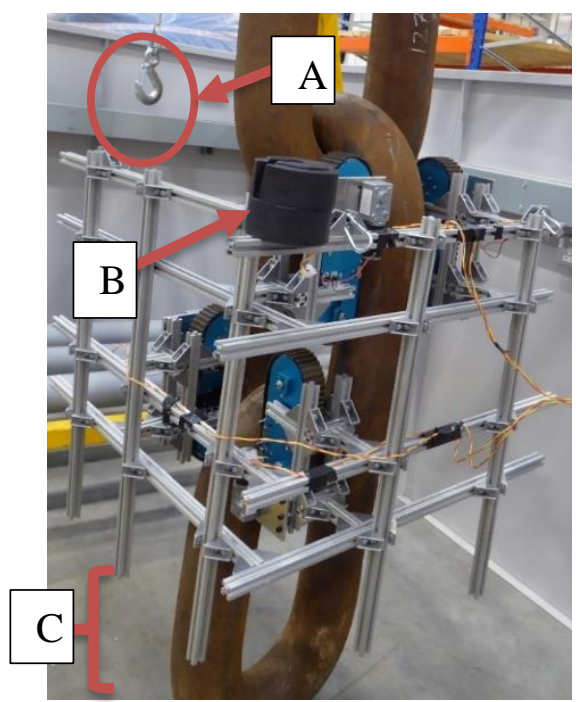

A- Detached safety cables, B- External weights (10N -50N), C - Robot not resting on the ground

Figure 19: Stability test against external loads

\section{Conclusions and Further work}

A prototype tracked-wheel magnetic adhesion robot is presented as a platform for mooring chain applications. Optimization of a neodymium permanent magnet adhesion module to obtain a required adhesion force was carried out by using FEA software package COMSOL Multiphysics and the simulated results were validated against the experimental results. A 
light weight, magnetic adhesion robot with orthogonal crawler units (tracked wheel crawler) has been prototyped and tested. The complete robot system was tested on a threelink mooring chain segment to study climbing capability and stability against external forces.

Future work to improve the climbing robot will introduce an active control mechanism that can correct the robot when it starts slipping or slightly changing its path due to external forces or mooring chain surface conditions. Since mooring chains are amphibious structures, the robot should be able to travel underwater. Therefore, it will be necessary to marinise motors and controllers to setup an underwater laboratory trial. A straight (consecutive links are orthogonal to each other) mooring chain was used in the present study. In practice, chain links can be misaligned (misalignment 5-20 degrees) and twisted relative to each other, Future work will attempt to improve the design to overcome the misalignment of chain links by increasing the degrees of freedom in the crawler units.

\section{Acknowledgement}

This research work has been funded by the London South Bank Innovation Centre (LSBIC), the National Structural Integrity Research Centre (NSIRC) and TWI (NDT department), Cambridge. The work is supported by InnovateUK with grant 102905 RIMCAW [19].

\section{References}

[1] R. B. Gordon, M. G. Brown, E. M. Allen and DNV GL, "Mooring Integrity Management: A State-of-the-Art Review," in Offshore Technology Conference, Houston, Texas, 2014.

[2] P. Elman, . J. Bramande, . E. Elletson and K. Pinheiro, "Reducing Uncertainty Through the Use of Mooring Line Monitoring," in Offshore Technology Conference, Rio de Janeiro, Brazil, 2013.

[3] Kai-tung Ma, H. Shu, S. Philip and D. Arun, "A Historical Review on Integrity Issues of Permanent Mooring Systems," in Offshore Technology Conference, Houston, Texas, 2013.

[4] Á. Angulo, G. Edwards, S. Soua and T.-H. Gan, "Mooring Integrity Management: Novel Approaches Towards In Situ Monitoring," in Structural Health Monitoring Measurement Methods and Practical Applications, Intechopen, 2017, pp. 87-108.

[5] Noble Denton Europe Limited, "Floating production system -JIP FPS mooring integrity," Health And Safety Executive, Aberdeen, 2016.

[6] J. Rudlin, "Multi-channel ultrasonic inspection of a mooring chain for fatigue cracks," in European Conference on Non-Destructive Testing, Prague, Czech Republic, 2014.

[7] P. S. Lowe, R. . M. Sanderson, N. . V. Boulgouris, A. G. Haig and W. Balachandran, "Inspection of Cylindrical Structures Using the First Longitudinal Guided Wave 
Mode in Isolation for Higher Flaw Sensitivity," IEEE Sensors Journal, vol. 16, no. 3, pp. 706-714, 2016.

[8] A. G. Ruiz, T. P. Sattar, . C. M. Sanz and B. S. Rodriguez-Filloy, "Inspection of floating platform mooring chain with a climbing robot," in 17th International Conference on Climbing and Walking Robots and the Support Technologies for Mobile Machines, Poznań, Poland, 2014.

[9] G. R. Edwards, . S. Kokkorikos, A. Garcia, . C. Patton and . T. Sattar, "www.moorinspect.eu," 2013.2 Available: http://www.moorinspect.eu/publications/NDT2012MoorInspect_latest.pdf. [Accessed 21 December 2015].

[10] P. Weiss, F. Andritsos, F. Schom and A. Fidani, "Innovative Robotic Solutions for the Survey and Certification of Ships and Mobile Offshore Units," in COMPIT, Siguenza, Spain, 2004.

[11] J. L. García, E. García, C. M. Suárez, . D. Blanco and . N. Beltrán, “Automated Offshore studless chain inspection system," in 16th WCNDT - World Conference on NDT, Montreal, Canada, 2004.

[12] S. Williams , “cordis.europa.eu," 14 March 2008. [Online]. Available: http://cordis.europa.eu/docs/publications/1216/121625181-6_en.pdf. [Accessed 10 December 2015].

[13] "Autonomous Robotic System for the Inspection of Mooring Chains," Project consortium report.

[14] Welapetage, “http://www.welaptega.com/," Welapetage, [Online]. Available: http://www.welaptega.com/services/subseameasurement/. [Accessed 2506 2016].

[15] M. O. F. Howlader, "Development of a Wall Climbing Robot and Ground Penetrating Radar System for Non-Destructive Testing of Vertical Safety Critical Concrete Structures," PhD thesis -London South Bank University, London, 2016.

[16] M. O. F. Howlader and T. . P. Sattar, "Finite Element Analysis based Optimization of Magnetic Adhesion Module for Concrete Wall Climbing Robot," International Journal of Advanced Computer Science and Applications, vol. 6, no. 8, pp. 8-18, 2015.

[17] W. Shen, J. Gu and Y. Shen, "Permanent Magnetic System Design for the Wallclimbing Robot," in IEEE International Conference on Mechatronics \& Automation, Canada, 2005.

[18] M. O. f. Howlader and T. P. Sattar, "Development of Magnetic Adhesion Based Climbing Robot for Non-Destructive Testing," in Computer Science and Electronic Engineering Conference (CEEC), University of Essex, UK, 2015.

[19] InnovateUK, Robotics and Autonomous Systems, ref 102905: Robotic Inspection of Mooring Chains in Air and Water (RIMCAW) 